\title{
La plenitud hermética del Derecho: ¿mito o realidad? Un acercamiento a la discusión sobre si los jueces crean Derecho
} The hermetic plenitude of Law: myth or reality? An approximation to the discussion about whether judges create Law

\author{
Frank Harbottle Quirós \\ Universidad de Costa Rica \\ frankharbottle@gmail.com
}

Recibido: 14/06/18 | Aceptado: 16/10/18

RESUMEN: El objetivo del presente trabajo es definir y caracterizar la plenitud hermética del Derecho brindando una aproximación desde sus orígenes. Se estudia este principio partiendo delos principales modelos de la función judicial (el formalismo jurídico, el realismo jurídico norteamericano, el positivismo de Kelsen, la discreción judicial de Hart y el modelo de la única respuesta correcta de Dworkin), concluyéndose, que este puede tener al menos dos significados: uno absoluto y uno relativo, siendo más aceptable en la actualidad el segundo, dada la importancia que han adquirido, en general, los principios en la aplicación del Derecho.

PALABRAS CLAVE: laguna, ley, plenitud, principios generales.

ABSTRACT: The objective of this paper is to define and characterize the hermetic plenitude of Law, providing an approximation from its origins. This principle is studied starting from the main models of the judicial function (legal formalism, american legal realism, Kelsen's positivism, Hart's judicial discretion and the model of Dworkin's only correct answer), concluding that this may have less two meanings: one absolute and one relative, the second being more acceptable nowadays, given the importance that, in general, the principles in the application of Law have acquired.

KEYWORDS: legal vacuum, law, plenitude, general principles. 


\section{SUMARIO}

I. Introducción. II. El principio de plenitud hermética del Derecho: orígenes y conceptualización. III. Los modelos de la función judicial y la plenitud hermética del Derecho. III.1. El formalismo jurídico. III.2. El realismo jurídico norteamericano. III.3. El modelo positivista de Kelsen y la discreción judicial de Hart. III.4. El modelo de la única respuesta correcta de Dworkin. IV. La plenitud hermética del Derecho en el contexto actual. V. Conclusiones. Bibliografía.

\section{Introducción}

En este artículo, en un primer apartado, se conceptualiza el principio de plenitud hermética del Derecho y se da una aproximación sobresus orígenes. Luego, se procede con su estudio partiendo delos principales modelosde la función judicial, concretamente, el formalismo jurídico, el realismo jurídico norteamericano, el positivismo de Kelsen y la discreción judicial de Hart, hasta descender al modelo de la única respuesta correcta de Dworkin.Posteriormente se realizan unas breves reflexiones sobre el dogma de la plenitud hermética del Ordenamiento jurídico en el contexto actual. Finalmente, se exponen las conclusiones de este trabajo.

\section{El principio de plenitud hermética del Derecho: orígenes y conceptualización}

Como una primera precisión cabe acotar que, para los efectos de este trabajo, los conceptos de Derecho y Ordenamiento jurídico serán utilizados como términos semejantes.

La definición del concepto de Derecho es una de las cuestiones más controvertidas en la Filosofía del Derecho. Su importancia no es menor. De ello, dependerán los alcances de principios como la plenitud hermética.

A pesar de los grandes esfuerzos de innumerables juristas y filósofos durante los últimos 2500 años, no se ha podido lograr un concepto inequívoco y generalmente aceptado del término "Derecho". Este concepto es, ayer como hoy, temporalmente dependiente y altamente polémico (Rüthers 2009, pp. 31 y 43).

\section{DERECHO GLOBAL. ESTUDIOS SOBRE DERECHO Y JUSTICIA}


Tal y como lo expone Nieto (2003, pp. 13, 35-36), aún nos encontramos ante una encrucijada de opciones irreconciliables: el Derecho normativo puro de corte kelseniano, el Derecho conformado por valores como la justicia o el bien común y, en fin, el Derecho de corte sociológico.

Dependiendo del concepto de Derecho del que se parta, así será más o menos la concepción que se tendrá sobre las facultades y potestades del juez, a efectos de concluir si este puede o no "crear" Derecho.

La doctrina tradicional no sólo supone una división tajante entre la creación y la aplicación del Derecho, la cual tiene sus raíces en la Ilustración, la Revolución Francesa y la codificación napoléonica que es una consecuencia casi necesaria de la doctrina de división de poderes, sino que además exige -para que los jueces estén en condiciones de cumplir su función-que el Derecho les suministre la posibilidad de resolver todos los casos mediante la aplicación de las normas generales. Esto implica que el Derecho ha de ser completo y coherente, en el sentido de que debe contener una solución para todo problema que sea sometido al juez y que no haya dos o más soluciones incompatibles para el mismo caso (Bulygin, 2003, p. 22).

El dogma de la plenitud, se ha considerado una nota constitutiva de los Ordenamientos jurídicos y una cláusula básica de su seguridad, sobre todo, en la época de la codificación de los siglos XVIII y XIX en la que regía la idea del sistema completo y coherente.

En la obra Del espíritu de las Leyes (1748), Montesquieu señala que las sentencias de los tribunales deben ser fijas, hasta el punto que deben corresponder siempre al texto expreso de la ley (1998, pp. 108-109). En su criterio "[...] Los jueces de la nación no son, más que el instrumento que pronuncia las palabras de la ley, seres inanimados que no pueden moderar ni la fuerza ni el rigor de las leyes [...]" (1998, p. 112).

Sostiene Frosini (1995, p. 76), que el principio afirmado en la época del Iluminismo, según el cual el juez es simplemente la bouche de la loi, cuyas palabras repite sin alterarlas, refleja, en realidad, una ideología precisa del poder 
político del soberano, en cuanto que éste representa un criterio útil para limitar el poder judicial en el momento interpretativo.

Con esta ideología dominante en la filosofía del Derecho y la política europea del siglo XIX, la labor de los jueces se limitaba a subsumir los hechos del caso que se les presentaba bajo la norma jurídica general.

La cultura jurídica de la codificación, fundada en algunos asentados tópicos de la Ilustración, trazaba una muy nítida frontera entre crear y aplicar el Derecho. La primera era función exclusiva del legislador, la segunda, del juez. Así como el legislador se presenta como un sujeto políticamente libre que puede dar vida a su voluntad normativa sin ataduras ni restricciones, el juez aparece como un sujeto estrictamente vinculado al Derecho. Bajo esta concepción logicista o estrictamente cognoscitiva, no cabe ninguna creación judicial del Derecho. Interpretar y aplicar el Derecho se conciben entonces como rigurosas operaciones lógicas que deben conducir siempre a un resultado unívoco "pre-constituido" por el Derecho objetivo (Prieto, 2014, p. 215).

La ley por excelencia era el código, cuyo modelo histórico durante todo el siglo XIX estaría representado por el Código civil napoleónico. En los códigos se encontraban reunidas y exaltadas todas las características de la ley, a saber, la voluntad positiva del legislador, capaz de imponerse indiferenciadamente en todo el territorio del Estado y que se enderezaba a la realización de un proyecto jurídico basado en la razón (la razón de la burguesía liberal, asumida como punto de partida); el carácter deductivo del desarrollo de las normas, la generalidad y la abstracción, la sistematicidad y la plenitud (Zagrebelsky, 2011, p. 32).

El dogma de la plenitud del Derecho parte de que el Ordenamiento jurídico tiene una norma para regular cada caso, rechazando, por ende, las lagunas.

Las lagunas, en palabras de Segura (1989, p. 289), aluden a la ausencia de regulación de una determinada situación que exige una respuesta por parte del Derecho.

Según lo apunta Prieto (2014,p.123), el dogma de la plenitud del Derecho ha sido entendido como aquella propiedad de integridad o completud del sistema, 
el cual dispone siempre de una cualificación normativa para cualquier caso o supuesto de hecho.

Este principio consiste en afirmar que en el Ordenamiento jurídico siempre existe una norma, formulada o implícita, que permite resolver jurisdiccionalmente cualquier problema que se suscite. Si bien, todo Ordenamiento jurídico formulado, está plagado de imperfecciones y de vacíos, siempre existe en la técnica jurídica algún medio de llenar jurisdiccionalmente esas imperfecciones y esos vacíos; y existe necesariamente porque así lo implica la esencia misma del Derecho (Laborde, 1947, p. 24).

Para Cossio (2005, p. 202), siendo el Derecho una totalidad hermética, el Juez no puede crear la norma general en que fundará su resolución, porque semejante hipótesis significa que el caso se juzgará por una norma creada después del hecho, cosa que contraría otros supuestos del orden jurídico.

Este postulado de plenitud surge ante la necesidad de hacer compatibles dos exigencias del Derecho moderno íntimamente unidas al proceso de monopolización jurídica del Estado legislativo, a saber: que el juez no puede negarse a fallar (prohibición del non liquet) y que debe hacerlo precisamente con arreglo a normas preestablecidas (Prieto, 2014, p. 123).

Según lo expone Latorre (2012, p. 84), del deber inexcusable de resolver no deriva la plenitud del orden jurídico, sino al contrario: dado que está impuesta esa obligación, ha de considerarse al orden jurídico capaz de facilitar soluciones a todos los casos de la práctica.

Los jueces, como operadores jurídicos, tienen la obligación de resolver cualquier caso que les presente $\mathrm{y}$, a su vez, tienen prohibido negarse a dictar una sentencia argumentando inexistencia de normas específicas para el caso puesto a su consideración.

A criterio de Asís (1995, pp. 29-31), la plenitud se presenta como una directriz para los operadores jurídicos que deben comportarse como si el Ordenamiento fuera completo, de ahí que se hable de dos sentidos del término "plenitud" del Derecho: absoluto (lleva aparejada la existencia de normas que 
solucionasen, por decirlo de alguna manera, todos los problemas) y relativo (admitiría la inexistencia de normas específicas en la solución de determinados problemas, pero la existencia se mecanismos para integrar estos problemas dentro del Ordenamiento).

Según se ha expuesto, durante la mayor parte de los siglos XIX y XX la doctrina dominante sobre la aplicación del Derecho fue la llamada teoría de la subsunción, la cual, aparte de ser una tesis metodológica, se trata de una posición política y filosófica que identifica al Derecho con la ley.

Las consideraciones expuestas dan pie al estudio del principio de plenitud del Ordenamiento jurídico a la luz de distintos modelos de la función judicial.

\section{III . Los modelos de la función judicial y la plenitud hermética del Derecho}

En la historia del pensamiento jurídico se han desarrollado distintos modelos que explican la función judicial, concretamente en lo relativo a si el juez crea o no Derecho.

En las próximas líneas se expondrán cuatro concepciones que se estima son las más relevantes o emblemáticas, a saber: 1) el formalismo jurídico; 2) el realismo jurídico norteamericano (quedará para un posterior trabajo el estudio del realismo escandinavo representado por Axel Hägerström), 3) el positivismo de Kelsen y la discreción judicial de Hart y 4) el modelo de la única respuesta correcta de Dworkin. Al finalizar la exposición de cada modelo, se brindará una aproximación en cuanto a cómo se visualiza el principio de plenitud hermética del Ordenamiento jurídico en cada uno de ellos.

\section{III.1. El formalismo jurídico}

Desde esta postura, la labor del juez se limita a una actividad mecánica, a la mera aplicación de las normas al caso concreto, al estimarse que el Derecho es

\section{DERECHO GLOBAL. ESTUDIOS SOBRE DERECHO Y JUSTICIA}


un sistema completo y cerrado en el que pueden deducirse soluciones para todos los casos posibles. Estamos en presencia del modelo silogístico que da origen al principio de plenitud hermética del Ordenamiento jurídico.

De acuerdo con esta concepción, el Derecho ha de ser completo y coherente, en el sentido de que debe contener una solución para todo problema que sea sometido al juez y que no haya dos o más soluciones incompatibles para el mismo caso (Bulygin, 2003, p. 22).

Siguiendo a García (2012, pp. 95-97), este racionalismo logicista predominó durante casi todo el siglo XIX, encontrándose en su máxima expresión y de manera más influyente en Europa continental en la Escuela de la Exegesis, en Francia, y en la Jurisprudencia de Conceptos, en Alemania, ambas coincidieron en muchas ideas básicas sobre el sistema jurídico y sobre el papel de los jueces en la aplicación del Derecho, básicamente en cuanto a que: i) el sistema jurídico es completo (no hay lagunas), es coherente (no tiene antinomias) y sus prescripciones son claras, proporciona solución indubitada para cualquier caso que conforme a Derecho deba resolverse; ii) los jueces no hacen ni tienen que hacer más que simples silogismos, elementales razonamientos lógicos; la decisión judicial nace de un automatismo razonador; no queda sitio para valoraciones personales del que juzga, no hay márgenes de discrecionalidad, el juez ni crea ni recrea Derecho ni añade nada al Derecho que halla, acabado, completo y claro.

Al referirse a esta posición llamada formalista, Carrió (1986, p. 64) apunta que suele ser caracterizada como una variedad de positivismo jurídico, siendo que la variante más influyente en nuestro medio es heredera, consciente o no, de la jurisprudencia conceptual alemana, que mereció primero la adhesión entusiasta y luego el cáustico repudio de Ihering. En el mundo anglosajón hubo también una variedad de formalismo protagonizada por algunos epígonos de Austin que, apartándose del fundador de la Analytican Jurisprudence, creyeron que toda la faena de los juristas consiste en la ordenación y sistematización de los conceptos jurídicos de diverso nivel y que la de los jueces se agota en deducir soluciones correctas a partir de reglas predeterminadas. 
Estamos, así, ante una manifestación histórica muy importante de las llamadas teorías de la única respuesta correcta: para cada caso que en sede jurídica haya de decidirse, el Derecho proporciona una y solo una solución, que será la correcta. Lo único que el juez tendrá o tendría que hacer sería descubrir cuál es esa respuesta correcta única predeterminada.

Otros autores como Aguiló (2012, pp. 129-132) han denominado a esta tesis como "deductivismo extremo", el cual consiste en considerar que el Derecho objetivo es completo y cerrado, de forma que suministra todos los criterios necesarios para resolver todos los casos posibles, por lo que la argumentación resulta inútil; es algo tan vano como pretender argumentar en favor de una operación aritmética.

De lo anterior se colige que el formalismo jurídico patrocina un modelo silogístico, basado en la subsunción, donde el juez lleva a cabo una labor racionalmecánica. Predica que el Ordenamiento jurídico, entendido como las normas, es pleno y siempre ofrece una respuesta a los problemas que se plantean, no existiendo casos difíciles.

\section{III.2. El realismo jurídico norteamericano}

De acuerdo con Atienza (2012, pp. 289-290), en un sentido muy amplio, concepciones jurídicas realistas serían todas las de carácter antiformalista, esto es, las que dieron lugar a la "revuelta contra el formalismo".

El debate en torno a la discreción judicial y sus límites cobró gran relevancia dentro de la teoría del Derecho a partir de los años treinta del siglo XX. El ideal de completud y la visión formalista de los jueces como meros instrumentos de la voluntad legislativa recibieron un fuerte embate desde corrientes como la del realismo jurídico americano. A pesar de que el realismo más extremo, que presentó la teoría jurídica como una teoría psicologista de la adjudicación de normas, no tuvo una influencia duradera, despertó el interés por el análisis de los procesos de decisión judicial y su relación con la producción 
normativa (Iglesias, 1999, p. 21).

Frente al deductivismo de la posición formalista, a fines del siglo XIX y principios del siglo XX, se da en el mundo anglosajón una importante reacción, representada por el denominado "realismo jurídico norteamericano", así como en Alemania la corriente conocida como "escuela del Derecho libre" que -aunque con menos difusión y trascendencia-comparte su carácter radicalmente crítico al formalismo (Duquelsky, 2015, p. 129).

Conforme lo refiere Nino (1996, p. 44), entre otras, hay una importante corriente del pensamiento jurídico que se desarrolló de manera dinámica en los Estados Unidos y los países escandinavos, con escritores tales como Holmes, Llewellyn, Frank, Olivecrona, Illum, etc., que muestran lo que se ha llamado "una actitud escéptica ante las normas jurídicas".

Fue en Estados Unidos de América donde la "revuelta contra el formalismo" tuvo más fuerza, movimiento iniciado por el juez Oliver W. Holmes que, frente al peso de la tradición, hizo hincapié en los elementos empíricos y pragmáticos del Derecho, debiéndosele a él la definición del Derecho en términos de predicciones sobre lo que los jueces harán (Atienza, 2012, p. 292).

En palabras de Holmes (2012)

Si quieres conocer lo que es el Derecho, y nada más que el Derecho, debes mirarlo como lo haría un hombre malo, a quien solo le importan las consecuencias materiales que tal conocimiento le permite predecir, y no como lo hace un hombre bueno, quien encuentra las razones para su conducta -se hallen o no en el Derecho- en las más vagas sanciones de su conciencia (p. 58).

En el ámbito anglosajón, surgió el movimiento intelectual jurídico y político denominado Critical Legal Studies (CLS), originado en la década de los sesenta y setenta del siglo XX, originado en ciertas universidades de los Estados Unidos de América, liderado por David M. Trubek y su discípulo Duncan Kennedy. 
El CLS constituye un ataque directo a la seguridad jurídica, sobre todo, en lo que se refiere al Derecho Judicial con sus intentos de politizar abusivamente la interpretación del Derecho, mediante el reforzamiento del arbitrio judicial. Estos autores creen que la previsibilidad de las decisiones judiciales provienen más del contexto en que esas decisiones son adoptadas, que de las propias normas jurídicas. Esta tesis se encuentra ya implícita en las teorías de los realistas Holmes y Llewellyn que mostraban cómo la clase social, la educación de los jueces incidía en las decisiones que tomaban. Así, el realismo pretendía buscar seguridad jurídica en una certeza científica y, para ello, abandonó el culto a la norma y lo sustituyó por el estudio empírico y cuantificable de los componentes de la decisión judicial (Marcos, 2008, p. 780).

Holmes entiende por Derecho "Las profecías acerca de lo que los tribunales harán realmente..." (2012, p. 60). Llewellyn, por su parte, considera que el abogado desea saber para poder aplicar el conocimiento de antemano a un tribunal concreto cuando le corresponda en una próxima apelación $(2015$, p. 11).

En relación con los jueces, los realistas subrayan el papel que estos juegan en la creación del Derecho, tienden a difuminar la distinción tradicional entre creación y aplicación del Derecho, rechazan el modelo silogístico, la "jurisprudencia mecánica" como tesis descriptiva sobre la aplicación del Derecho y son escépticos en materia de justificación de las decisiones. Autores como Frank son "escépticos frente a los hechos". Es decir, entienden que, en la mayoría de las ocasiones, es imposible predecir cómo será decidido un pleito, pues ello no depende tanto de las normas, cuanto, de los hechos, lo cual obedece, sobre todo, a elementos de carácter puramente subjetivo o idiosincrásico; la consecuencia es que se renuncia a la certeza jurídica por considerarlo un ideal inalcanzable o, mejor dicho, un mito (Atienza, 2012, pp. 295-296).

De ahí que Frank (2009, p. 153) afirme que la pasión y los prejuicios pueden desempeñar un papel importante en la decisión del juez, siendo imposible deshacerse de las emociones en el campo de la justicia. Ante lo cual, lo mejor que se puede esperar es que las emociones del juez se vuelvan más equilibradas, más capaces de una articulación detallada. 
El realista reconoce el hecho básico de que a menudo los textos jurídicos cabe entenderlos de maneras distintas, ninguna de las cuales es ni más ni más ni menos "correcta" que las demás; mas tampoco afirma que esto sea así en todos los casos (Haba, 2002, p. 516).

En opinión de Salas (2009, pp. 223-227), aún y cuando los postulados del realista son generalmente correctos, la coherencia lógica de sus afirmaciones muchas veces impecable, la fundamentación indiscutible, la pertinencia de sus fundamentos es cuestionable, de ahí que no sin razón suele suceder que las grandes obras del realismo jurídico de antaño (las de Frank, Holmes o Llewellyn), no hayan sido nunca respondidas de una forma convincente. La política que aquí opera es la del silencio y la indiferencia, mientras que los debates y discusiones continúan, como si tales obras no existiesen o como si sus autores nunca hubiesen profesado palabra alguna sobre el fenómeno jurídico.

De lo expuesto cabe concluir que el realismo jurídico presenta diversas versiones, todas ellas, antiformalistas. Al no estar el juez subordinado en sentido estricto a la ley, al realista le es indiferente el principio de plenitud hermética del Ordenamiento jurídico. Las decisiones de los jueces son consecuencia de su subjetividad y de factores extrajurídicos, de ahí que haya escepticismo, sea hacia las normas, los hechos o las personas que toman las decisiones judiciales.

\section{III.3. El modelo positivista de Kelsen y la discreción judicial de Hart}

Calvo plantea que la Teoría positivista del derecho en sentido estricto se desarrolló esencialmente en el siglo XIX, siendo que las ideologías jurídicas modernas e ilustradas avanzaron algunos de sus presupuestos fundamentales (2008, pp. 208210). Por lo común, en las reconstrucciones anglosajonas de los precedentes del positivismo jurídico se menciona casi exclusivamente al respecto a John Austin y se reiteran como antecedentes las obras de Thomas Hobbes y Jeremy Bentham. La Teoría positivista del derecho del siglo XX, discurre por sendas paralelas. Primero, Hans Kelsen y luego Herbert L. Hart contribuirán decisivamente a sentar las bases de una corriente que habría dominado el pensamiento jurídico 
de este siglo. Kelsen renovó epistemológicamente los fundamentales de la Teoría positivista del derecho. La construcción de una teoría normativista-imperativista, general y pura del derecho, basado en la separación del ser y el deber ser, la autonomía de lo jurídico y una teoría de la validez coherente con las premisas anteriores resultaran en un producto teórico perfectamente comparable con el de Austin. Mayores diferencias se encuentran en la propuesta de Hart, quien dio un importante paso importante reivindicando la vigencia de las tesis positivistas y abriendo camino a una nueva época del pensamiento jurídico dominada por la pujanza del positivismo jurídico.

El positivismo, conocido por autores como Atienza bajo la denominación "normativismo", parte de la idea de que el Derecho consiste fundamentalmente en normas, constituyéndose quizás en la concepción más difundida del siglo XX $\mathrm{y}$, sin duda, la más desarrollada desde el punto de vista teórico. Pese a que es muchas veces una concepción "difusa" del Derecho que puede combinarse -en dosis e intensidades variables- con muchas otras, quizás sea posible reducir todos los tipos de normativismo del siglo XX a dos modelos básicos: el normativismo formalista de Hans Kelsen y el normativismo analítico (o positivismo analítico) representado de manera paradigmática por la obra de Herbert L. A. Hart (Atienza 2012, pp. 298-299).

H.L.A. Hart y su obra El concepto de derecho (1961), representa para el mundo anglosajón lo que significa Hans Kelsen y su Teoría Pura del Derecho (1934) para la tradición de origen continental europea, la versión estándar del positivismo jurídico.

Kelsen y Hart son de los autores positivistas que parten de la idea de que una cosa es describir o explicar lo que es el Derecho y otra valorarlo moralmente; igualmente, los separa del iusnaturalismo -o de la mayor parte de los iusnaturalista- la idea de que el Derecho es creado y modificado exclusivamente por actos humanos (Atienza, 2012, p. 299).

De acuerdo con Kelsen, el orden jurídico siempre es aplicado por un tribunal en un caso concreto, aun en el caso en que el orden jurídico, en opinión 
del tribunal no contenga ninguna norma general que regule positivamente la conducta del demandado o acusado. Desde la perspectiva de este autor:

es posible que el orden jurídico autorice al tribunal, cuando no puede establecer ninguna norma jurídica general que imponga al demandado o acusado la obligación cuya violación afirma el demandante privado o el acusador público, a no rechazar la demanda, ni a absolver al acusado, sino a hacer lugar a la primera o condenar al segundo, cuando tenga la falta de tal norma jurídica general por cosa injusta, inaceptable, es decir, por cosa no satisfactoria. Ello significa que el tribunal queda facultado para producir una norma jurídica individual para el caso que se le presenta, cuyo contenido de ninguna manera está predeterminado por una norma general de derecho de fondo producida por vía legislativa o consuetudinariamente. En ese caso, el tribunal no aplica tal norma jurídica, sino la norma jurídica que lo faculta para crear nuevo derecho de fondo. Se suele decir que el tribunal está facultado para actuar como legislador. No es ello del todo exacto si por legislación se entiende la producción de normas jurídicas generales. Puesto que el tribunal sólo es autorizado para producir una norma individual, válida para el único caso que le es presentado. Esa norma individual es producida por el tribunal aplicando una norma general que considera deseable, que estima "justa", pero que el legislador positivo ha omitido promulgar. Sólo como aplicación de semejante norma general no positiva, cabe justificar, como justa, la norma individual impuesta por el tribunal (1993, p. 253).

El normativismo formalista de Kelsen presenta algunos rasgos en común con el formalismo jurídico tradicional, por ejemplo: la idea de que un sistema jurídico es completo (carente de lagunas), la importancia de construir un sistema de conceptos, de considerar al Derecho como un sistema cerrado con respecto a la sociedad, etc.; pero se diferencia radicalmente en la manera de entender la interpretación y la aplicación del Derecho, en tanto reconoce el papel creador del Derecho por parte de los jueces (o de los órganos administrativos) al relativizar 
la distinción entre la creación y la aplicación de las normas (Atienza, 2012, pp. 300-303).

Kelsen, en sus obras más importantes sostuvo la tesis de que el Derecho no presenta lagunas o contradicciones lógicas, aunque, en cambio, sí admitió la existencia de indeterminaciones lingüísticas, lo que hace, según él, que el Derecho presente a los jueces no una sola solución sino varias alternativas. Sin embargo, con respecto a la tesis de que el Derecho es necesariamente completo y coherente, Kelsen de ningún modo sugiere que esta tesis, sea relevante para su posición positivista (Nino, 1996, p. 37).

Para Kelsen "en el caso de que no sea posible la aplicación de una norma jurídica aislada, es posible en cambio la aplicación del orden jurídico, y ello también constituye aplicación de derecho" (1993, p. 255).

Por otra parte, la posición de Hart, puede sintetizarse así: el Derecho no tiene un carácter cerrado, pues la normas se expresan en un lenguaje natural, una de cuyas características centrales es la vaguedad potencial o textura abierta: los conceptos jurídicos no pueden definirse de manera totalmente precisa, pues además de zonas claras de aplicación (o de no aplicación) de las expresiones existe siempre, al menos potencialmente, una zona de penumbra, imposible de cerrar a priori; existiendo casos fáciles (los que caen en la zona de claridad), en los que el intérprete -el juez- no ejerce ninguna discrecionalidad, sino que se limita a descubrir un significado ya existente, y de casos difíciles (los que caen en la zona de la penumbra) en los que el juez necesariamente tiene que decidir, esto es, ejerce su discrecionalidad, aunque no lo haga de manera arbitraria (Atienza, 2012, p. 304-306).

Hart afirma que la textura abierta del Derecho significa que hay áreas de conducta donde mucho debe dejarse para que sea desarrollado por los tribunales (1961, p. 168). Desde su óptica "[...] Es imposible eliminar esta dualidad de un núcleo de certeza y una penumbra de duda, cuando se trata de colocar situaciones particulares bajo reglas generales. Esto imparte a todas las reglas un halo de vaguedad o "textura abierta" [...]" (pp. 152-153). 
De acuerdo con Hart, el formalismo y el escepticismo ante las reglas “[...] son el Escila y el Caribdis de la teoría jurídica; son grandes exageraciones, que resultan saludables cuando se corrigen entre sí. La verdad se encuentra en el medio [...]" (1961, p. 183).

Vemos, entonces, que el modelo positivista de Kelsen parte de que el sistema jurídico es completo, aspecto en que en cierta forma coincide con el formalismo jurídico, no obstante, admite la existencia de indeterminaciones lingüísticas, lo que hace, que no pueda hablarse de un único resultado correcto al momento en que los jueces resuelven, sino de un resultado posible entre varias alternativas.

En relación con el modelo positivista de la discreción judicial de Hart, este parte de que no se puede demostrar que una decisión judicial es la única correcta, pero es posible conseguir que se la acepte como el producto razonado de una elección imparcial bien informada, ello debido a que el Derecho no tiene un carácter cerrado, existiendo casos fáciles (caen en la zona de claridad), en los que el juez no ejerce ninguna discrecionalidad, sino que se limita a descubrir un significado ya existente, y de casos difíciles (caen en la zona de la penumbra) en los que el juez necesariamente tiene que decidir, esto es, ejerce su discrecionalidad, aunque no lo haga arbitrariamente, definiéndose por la ausencia de respuesta correcta. De ahí que, de una u otra forma, Hart admite la posibilidad de que en los casos difíciles no exista norma aplicable, por lo que no podría hablarse de una plenitud hermética del Ordenamiento jurídico en los términos del formalismo.

\section{III.4. El modelo de la única respuesta correcta de Dworkin}

Según lo apunta Atienza (2012, p. 319), Dworkin es el jurista más influente en las últimas décadas del siglo pasado, siendo que tomó como punto de partida el positivismo hartiano y critica lo que él considera como tesis centrales del positivismo más refinado, sin embargo, una de las particularidades es que él contempla el Derecho esencialmente no desde el punto de vista del legislador, sino desde la perspectiva del juez que ha de resolver un caso difícil, dando cuenta 
de un Estado democrático como sistema jurídico legitimado, donde existen un conjunto de reglas (tesis esta ultima que él atribuye a Hart), además de principios, los cuales son los materiales a utilizar para resolver litigios.

En general, frente a la idea positivista hartiana del Derecho caracterizado por su textura abierta, Dworkin y el anti-positivismo contemporáneo oponen una concepción del Derecho como un "producto acabado" y completo, y no inconcluso o abierto (Real, 2008, p. 423).

Dworkin plasmó su tesis central en la obra Los derechos en serio (2014). Al respecto anotó:

Ya no está tan claro que el sentido común o el realismo fundamenten la objeción de que no puede haber una respuesta correcta, sino sólo una variedad de respuestas aceptables, en un caso difícil. El argumento práctico que respalda esa afirmación está equivocado. $\mathrm{Al}$ argumento teórico lo contradicen las capacidades de quienes lo formulan, y aparentemente no se lo puede siquiera enunciar de una manera que no difumine sus pretensiones dentro del marco mismo de lo que intenta cuestionar. Algunos lectores no habrán quedado convencidos. Seguramente, no puede ser que en un caso auténticamente difícil, una de las partes simplemente se equivoque y la otra simplemente tenga razón. Pero, ¿por qué no? Es posible que la suposición de que una de las partes pueda tener razón y la otra se equivoque esté incorporada en nuestros hábitos de pensamiento en un nivel tan profundo que no podamos negarla coherentemente, por más escépticos o realistas que nos propongamos ser en tales asuntos. Eso explicaría nuestra dificultad para enunciar el argumento teórico de manera coherente. El "mito" de que en un caso difícil hay una única respuesta correcta es tan recalcitrante como afortunado. Ambas condiciones pueden constituirse en argumentos para demostrar que no es un mito (p. 411).

Conforme lo señala Iglesias (1999, p. 124), a lo largo de sus años Dworkin mantuvo la tesis de la única respuesta correcta y el rechazo a la necesidad técnica de discreción fuerte en los casos difíciles. Para justificar su posición desarrolló 
una amplia propuesta epistémica y filosófica: la teoría interpretativa del Derecho, que se presenta como un desafío a los principales presupuestos del positivismo y a las tesis indeterministas del escepticismo, pretendiendo, con ello, ofrecer una nueva perspectiva de aproximación al Derecho y argumentos para mostrar la existencia de una única respuesta correcta en los casos difíciles.

Sobre el problema de la única respuesta correcta, autores como Aarnio (1990) se han pronunciado en sentido diverso a Dworkin. Para Aarnio "no puede haber respuestas correctas en el razonamiento jurídico (tesis ontológica). Por consiguiente, tales respuestas tampoco pueden ser detectadas (tesis epistemológica y metodológica)" (pp. 24-25). Para dicho autor, el presuponer una respuesta correcta "no nos ayuda a servir mejor a la sociedad. Lo que realmente necesitamos es justificación racional” (p. 38).

En contra de lo que sostienen los positivistas en el sentido de que, en los casos difíciles, los jueces deciden en forma discrecional, Dworkin mantiene que esa discrecionalidad no puede darse, pues, si se diera, el juez invadiría la función del legislador, por lo que siempre -o casi siempre- existe una única respuesta para cada caso, porque siempre hay una teoría sustantiva de carácter moral y político (de entre las que se adecuan a los materiales del Derecho) que es la mejor, la más profunda; los jueces de carne y hueso no siempre serán capaces de encontrarla, y de ahí que Dworkin cree el modelo de un juez Hércules, dotado de capacidad, cultura, paciencia e ingenio sobrehumano, capaz de lograr esta hazaña (Atienza, 2012, pp. 320-321).

Es claro, entonces, que la posición dworkiniana contrasta con el positivismo hartiano, no en su modo de caracterizar los casos difíciles, sino en las implicaciones de su existencia respecto a la posibilidad de discreción fuerte. Dworkin sostiene que en los casos difíciles sigue existiendo una única respuesta correcta que el órgano judicial está jurídicamente obligado a identificar (Iglesias, 1999, pp. 250-256).

Dworkin retoma la idea de que el Ordenamiento jurídico está constituido no sólo por normas o reglas sino también por principios. 
La admisión de los principios generales como fuente del Derecho rompe la estatización del Derecho que se pretendió asegurar con el dogma de la completitividad del Ordenamiento. Además de lo dicho en el texto la distinción entre norma y principio se apoya -según Dworkin- en que estos tienen una dimensión que no poseen aquellas: la de peso o importancia (Cassagne, 2015, p. 65).

La posición de Dworkin (2014) se resume en estas palabras

Un positivista podría afirmar que los principios no pueden considerarse como derecho porque su autoridad, y mucho más su peso, son discutibles por naturaleza. Es verdad que generalmente no podemos demostrar la autoridad o el peso de un principio determinado como podemos a veces demostrar la validez de una norma, localizándola en un acta del Congreso o en la opinión de un tribunal autorizado. En cambio podemos defender un principio - y su peso - apelando a una amalgama de prácticas y de otros principios en la cual cuenten las implicaciones de la historia legislativa y judicial, junto con referencias a prácticas y sobreentendidos comunitarios (pp. 89-90).

Según lo expone Marinoni (2016, pp. 45-46), los principios son constitutivos del orden jurídico, revelando los valores o los criterios que deben orientar la compresión y la aplicación de las reglas frente a las situaciones concretas, sin que deba entenderse que su función es meramente complementaria o accesoria.

A manera de síntesis, cabe indicar que el modelo dworkiniano en cierto modo viene a revivir el tema de la única respuesta correcta y a fortalecer el dogma de la plenitud del Ordenamiento jurídico dándole importancia a los principios a partir de los cuales se desprende es posible lograr dicho cometido. De ahí que, desde su óptica, el juez carece de discreción, siendo posible que encuentre siempre una respuesta correcta en el Derecho preestablecido. 


\section{La plenitud hermética del Derecho en el contexto actual}

Los modelos de la función judicial expuestos presentan relevancia en la medida en que cada uno de ellos brinda una noción en relación con el tema de si los jueces "crean Derecho", lo cual se encuentra estrechamente vinculado con la concepción de si el Ordenamiento jurídico presenta una plenitud hermética.

La superación del dogma de la completud del Ordenamiento jurídico lleva a que hoy en día se hable de casos fáciles, difíciles y trágicos. Dentro de esta terminología seguida por Atienza (2013, pp. 123, 812-813), en los casos fáciles es posible acudir a cierto deductivismo, pues tiene una solución previa contenida en una regla del Ordenamiento jurídico. Los casos difíciles son supuestos en que, para establecer la premisa fáctica o la premisa normativa, así como justificar la decisión, no basta un único argumento. Los casos trágicos son aquellos en los que no es que haya más de una respuesta correcta, sino que no hay ninguna; es imposible realizar la idea de justicia a través del derecho.

Dependiendo del caso, para la aplicación jurídica adquiere relevancia la subsunción y/o ponderación como operaciones fundamentales. Al respecto Alexy (2012) ha indicado

Mientras la subsunción ha sido relativamente bien investigada, en lo que concierne a la ponderación, aún hay muchas preguntas por responder. Hay tres problemas básicos: el de la estructura, el de la racionalidad y el de la legitimidad. Entre estos problemas existen vínculos estrechos. La legitimidad de la ponderación en el derecho depende de su racionalidad. Cuanto más racional sea la ponderación, más legítima será la práctica de ponderaciones. Ahora bien, la estructura de la ponderación es decisiva para su racionalidad. Si los análisis revelaran que la ponderación no puede ser sino una decisión arbitraria, entonces sería cuestionable su racionalidad, así como su legitimidad en la jurisprudencia (pp. 23-24). 
Como método de aplicación jurídica, la ponderación ha adquirido el mismo rango categorial que la subsunción, hasta entonces dominante en la metodología clásica. Por ello, para autores como Borowski (2016, pp. 71-73, 99-100) la ponderación comparte una serie de características relevantes con la interpretación en el sentido de Kelsen y que podrá, por lo tanto, formar parte, sin mayores problemas, de la estructura jerárquica del Derecho, lo cual se confirma en el hecho de que en el sistema jurídico alemán, caracterizado por la estructura jerárquica del Derecho, se llevan a cabo ponderaciones en los diferentes niveles jerárquicos, sin que existan los menores indicios de problemas estructurales serios. Lo mismo se podrá afirmar en relación con otros Estados constitucionales. Partiendo de una comprensión diferenciada de estructura jerárquica y ponderación, esta última podrá ser integrada armónicamente en la primera.

En realidad las nuevas concepciones jurídicas se concentran más en la cultura del Derecho que en la cultura de la ley. Al presentar lagunas el Ordenamiento positivo, la idea ficticia de la plenitud del Derecho puede cobrar vida sobre la base de la integración que, en definitiva, orientan los principios generales del Derecho Natural supliendo la carencia normativa (Cassagne, 2015, pp. 18 y 93).

Sin duda, la temática estudiada pone en evidencia que la ponderación de principios presenta gran actualidad y está totalmente relacionada con la plenitud hermética del Ordenamiento jurídico.

\section{Conclusiones}

La doctrina tradicional ha planteado una división categórica entre la creación y la aplicación del Derecho, la cual tiene sus bases en la Ilustración, la Revolución Francesa y la codificación napoléonica como consecuencia de la clásica división de poderes. Surge así el dogma de la plenitud hermética del Ordenamiento jurídico, según el cual, el sistema jurídico, entendido en sentido normativo, presenta la propiedad de completitud o integridad, no admitiéndose, en consecuencia, que existan vacíos normativos o lagunas. 
A lo largo de la historia se han planteado diversos modelos de la función judicial, los cuales, de manera explícita o implícita se pronuncian sobre la plenitud hermética.

El formalismo jurídico patrocina un modelo silogístico, basado en la subsunción, donde el juez lleva a cabo una labor racional-mecánica. Predica que el Ordenamiento jurídico, entendido como normas, es pleno y siempre ofrece una respuesta a los problemas que se plantean, no existiendo casos difíciles.

El realismo jurídico presenta diversas versiones, todas ellas, antiformalistas. Al no estar el juez subordinado en sentido estricto a la ley, al realista le es indiferente el principio de plenitud hermética del Ordenamiento jurídico. Las decisiones de los jueces son consecuencia de su subjetividad y de factores extrajurídicos, de ahí que haya escepticismo, ya sea hacia las normas, los hechos o las personas que toman las decisiones judiciales.

El positivismo de Kelsen parte de que el sistema jurídico es completo, aspecto en que en cierta forma coincidecon el formalismo jurídico, no obstante, admite la existencia de indeterminaciones lingüísticas, lo que hace, que no pueda hablarse de un único resultado correcto al momento en que los jueces resuelven, sino de un resultado posible entre varias alternativas.

El modelo positivista de la discreción judicial de Hart parte de que el Derecho no tiene un carácter cerrado, existiendo casos fáciles (caen en la zona de claridad), en los que el juez no ejerce ninguna discrecionalidad, sino que se limita a descubrir un significado ya existente, y de casos difíciles (caen en la zona de la penumbra) en los que el juez necesariamente tiene que decidir, esto es, ejerce su discrecionalidad. Hart, de una u otra forma, admite la posibilidad de que en los casos difíciles no exista norma aplicable, por lo que no podría hablarse de una plenitud hermética del Ordenamiento jurídico en los términos del formalismo.

El modelo de Dworkin, revive el tema de la única respuesta correcta y fortalece el dogma de la plenitud del Ordenamiento jurídico, pero no entendido sólo como normas positivas o reglas, sino que le otorga gran importancia a los principios del Derecho a partir de los cuales estima es posible lograr dicho 
cometido, rechazando, en consecuencia, la discreción judicial.

El principio de plenitud hermética del Ordenamiento jurídico sin duda alguna ha evolucionado desde sus inicios. Si la completitud la entendemos como que el sistema jurídico tiene la habilidad de resolver cualquier cuestión puesta a consideración de los operadores jurídicos, existiendo una norma para cada una de todas las conductas posibles, estamos ante una fantasía (plenitud absoluta). En esos términos es un mito que debe ser abandonado de un modo definitivo. Si la plenitud hermética la concebimos como la exigencia de la eliminación de las lagunas o vacíos normativos del Ordenamiento jurídico, a partir no sólo de normas o reglas, sino también de principios, es posible afirmar que realmente podemos hablar de plenitud (relativa), de ahí la prohibición a los jueces de abstenerse de decidir (inexcusabilidad) ante la existencia de lagunas.

La concepción que tenga el juez del Derecho, así como el modelo o los modelos de función judicial que considere resultan ser más afines a su formación y concepción de mundo, son aspectos esenciales que definirán el grado de discrecionalidad que en su criterio tiene al momento de interpretar y aplicar el Derecho.

\section{Bibliografía}

Aarnio, A. (2001). La Tesis de la única respuesta correcta y el principio regulativo del razonamiento jurídico. Doxa, 8, 23-38. Recuperado de https://rua.ua.es/dspace/bitstream/10045/10797/1/Doxa8_01.pdf

Alexy, R. (2012). Teoría de la Argumentación Jurídica. Madrid: Centro de Estudios Políticos y Constitucionales.

Asís Roig, R. (1995). Jueces y normas. La decisión judicial desde el Ordenamiento. Madrid: Marcial Pons.

Atienza, M. (2013). Curso de Argumentación Jurídica. Madrid: Editorial Trotta.

Atienza, M. (2012). El Sentido del Derecho. Barcelona: Editorial Ariel. Borowski, M. (2016). La ponderación en la estructura jerárquica 
del derecho. En María Elósegui (Coord.), Los principios y la interpretación judicial de los derechos fundamentales (pp. 71100). Zaragoza: Fundación Manuel Giménez Abad de Estudios Parlamentarios y del Estado Autonómico.

Bulygin, E. (2003). Los jueces ¿crean derecho? En J. Malem, J. Orozco

y R. Vázquez (Eds.), La Función Judicial. Ética y Democracia (pp. 21-38). Barcelona: Gedisa.

Calvo, M. (2008). Positivismo Jurídico y Transformaciones del derecho.

Varios, Teoría y Metodología del Derecho (vol. II, pp. 201-222).

Madrid: Editorial Dykinson.

Carrió, G. (1986). Notas sobre Derecho y Lenguaje. Buenos Aires: Abeledo-Perrot.

Cassagne, J. (2015). Los grandes principios del derecho público, constitucional y administrativo. Buenos Aires: La Ley.

Cossio, C. (2005). La Plenitud del Ordenamiento Jurídico. Buenos Aires:

Editorial Los Andes.

Duquelsky Gómez, D. (2015). El rol del juez en una sociedad democrática.

Revista de Direitos e Garantias Fundamentais, 2(16), pp. 121-

148. Recuperado de http://www.ub.edu/dretaldret/documentos/

Duquelsky_sobre_jueces.pdf

Dworkin, R. (2014). Los derechos en serio. Barcelona: Ariel.

Frosini, V. (1995). La Letra y el Espíritu de la Ley. Barcelona: Ariel.

García, J. (2012). Razonamiento Jurídico y Argumentación. Nociones

Introductorias. España: Ediciones EOLAS.

Haba, E. (2002). Metodología realista-crítica y ética del razonamiento judicial: (realismo jurídico como alternativa práctica al discurso normativista de los jueces). Doxa, (25), pp. 503-531. Recuperado de http://www.cervantesvirtual.com/nd/ark:/59851/bmc2n5f6

Hart, H. (1961). El Concepto de Derecho. Buenos Aires: Abeledo-Perrot. Iglesias, M. (1999). El Problema de la Discreción Judicial. Una Aproximación al Conocimiento Jurídico. Madrid: Centro de Estudios Políticos y Constitucionales.

Kelsen, H. (1993). Teoría Pura del Derecho. México: Editorial Porrúa. 
Laborde, S. (1947). El problema de las lagunas de la ley y el principio de la plenitud hermética. Revista de la Escuela Nacional de Jurisprudencia. (35-36), pp. 23-56. Recuperado el 4 de agosto de 2018 desdehttp://historico.juridicas.unam.mx/publica/librev/rev/ revenj/cont/35/dtr/dtr3.pdf.

Latorre, A. (2012). Introducción al Derecho. Barcelona: Ariel.

Llewellyn, K. (2015). The Common Law Tradition. New Orleans: Legal legends.

Marcos, A. (2008). La Seguridad Jurídica: Su Configuración Actual. En Varios, Teoría y Metodología del Derecho (vol. II, pp. 763-785). Madrid: Editorial Dykinson.

Marinoni, L. (2016). Teoría General Del Proceso. Una Aplicación Neoconstitucional. San Salvador: Editorial Cuscatleca.

Montesquieu. (1998). Del espíritu de las Leyes. Madrid: Tecnos.

Nieto, A. (2003). Las limitaciones del conocimiento jurídico. Madrid: Editorial Trotta.

Nino, C. (1996). Introducción al Análisis del Derecho. Barcelona: Editorial Ariel.

Prieto, L. (2014). Apuntes de teoría del Derecho. Madrid: Editorial Trotta. Real, J. (2008). La Doctrina de la Completitud del Derecho Según el Anti-positivismo Jurídico Contemporáneo. En Teoría y Metodología del Derecho. (Vol.II), (pp. 423-447). Madrid: Editorial Dykinson.

Rüthers, B. (2009). Teoría del Derecho. Concepto, validez y aplicación del derecho. México: Editorial UBIJUS.

Salas, M. (2009). Debate sobre la utilidad de la metodología jurídica: una reconstrucción crítica de las actuales corrientes metodológicas en la teoría del Derecho. Revista Telemática de Filosofía del Derecho, 12, 205-231. Recuperado el 5 de agosto de 2018 desde http://www.rtfd. es/numero12/08-12.pdf.

Segura, M. (1989). El problema de las lagunas en el Derecho. Anuario de Filosofía del Derecho. (VI), 285-312. Recuperado el 26 de enero de 2019 desde https://www.boe.es/publicaciones/anuarios_derecho/ abrir_pdf.php?id=ANU-F-1989-10028500312_ANUARIO 
DE_FILOSOF\%CDA_DEL_DERECHO_El_problema_de_las_ lagunas_en_el_derecho

Wendell Holmes, O. (2012). La senda del Derecho. Traducción de José Ignacio Solar Cayón. Madrid: Marcial Pons.

Zagrebelsky, G. (2011). El derecho dúctil. Ley, derechos, justicia. Madrid: Editorial Trotta.

Cómo citar este artículo: Harbottle, F. (2019). La plenitud hermética del derecho: ¿mito o realidad? Un acercamiento a la discusión sobre si los jueces crean derecho. Derecho Global. Estudios sobre Derecho y Justicia, 4(11), pp. 117-141. DOI: 10.32870/dgedj.v0i11.185 
